\title{
Capacity and limits of associative memory in pigeons
}

\author{
ROBERT G. COOK, DEBORAH G. LEVISON, and SARAH R. GILLETT \\ Tufts University, Medford, Massachusetts \\ and \\ AARON P. BLAISDELL \\ University of California, Los Angeles, California
}

\begin{abstract}
How much information can a brain store over a lifetime's experience? The answer to this important, but little researched, question was investigated by looking at the long-term visual memory capacity of 2 pigeons. Over 700 sessions, the pigeons were tested with an increasingly larger pool of pictorial stimuli in a two-alternative discrimination task (incremented in sets of 20 or 30 pictures). Each picture was randomly assigned to either a right or a left choice response, forcing the pigeons to memorize each picture and its associated response. At the end of testing, 1 pigeon was performing at 73\% accuracy with a memory set of over 1,800 pictures, and the 2 nd was at $76 \%$ accuracy with a memory set of over 1,600 pictures. Adjusted for guessing, models of the birds' performance suggested that the birds had access, on average, to approximately 830 memorized picture-response associations and that these were retained for months at a time. Reaction time analyses suggested that access to these memories was parallel in nature. Over the last 6 months of testing, this capacity estimate was stable for both birds, despite their learning increasingly more items, suggesting some limit on the number of picture-response associations that could be discriminated and retained in the long-term memory portion of this task. This represents the first empirically established limit on long-term memory use for any vertebrate species. The existence of this large exemplar-specific memory capacity has important implications for the evolution of stimulus control and for current theories of avian and human cognition.
\end{abstract}

How does the brain encode, store, and retrieve an entire lifetime of experiences? Biological memory capacity has been extensively studied with regard to the short-term retention of recent information (Miller, 1956; Nelson, 2001), and a system with a limited capacity in the single digits has consistently been suggested. Such findings suggest that the brain may have multiple memory systems, and numerous longer term stores (e.g., procedural, episodic, long-term, semantic, associative, and reference memory) have been proposed to capture the extensive knowledge and memories stored beyond those of the recent past. One challenging issue concerns the storage capacity and information retrieval of these longer term memory mechanisms. Attempts to examine the capacity of such longer term memory stores have been limited and mainly computational (Dudai, 1997; Landauer, 1986; Standing, 1973). Although there is general agreement that the human capacity for recognizing pictorial information is considerable (Shepard, 1967; Stand-

\footnotetext{
This research was supported by a grant from the Animal Behavior program of the National Science Foundation to R.G.C., who thanks everyone in the Cook lab for assistance in conducting these experiments over the last 3 years and Taylor Johnson and Angie Koban for their comments on earlier drafts. Correspondence concerning this article should be addressed to R. G. Cook, Department of Psychology, Tufts University, 530 Bacon Hall, Medford, MA 02155 (e-mail: robert.cook@tufts.edu; home page, www.pigeon.psy.tufts.edu).
}

ing, 1973) and the storage needs for language use substantial, the empirical study of long-term memory capacity has been virtually absent because of the impractical requirements of testing humans over extended periods.

Nonhuman animals are similarly guided by a combination of acquired knowledge and recent experiences, but here as well, little effort has been directed at understanding the capacity of their longer term memory systems. Vaughan and Greene (1984) conducted the most extensive study of animal memory capacity. They showed that pigeons could discriminate among 320 randomly assigned pictorial stimuli ( 160 positive and 160 negative) in a successive go/no-go discrimination. On the basis of a smaller stimulus set (160), they further demonstrated that some of these memories endure for at least 2 years. There are some important limitations, however, to these findings. Their rate-based discrimination procedure and rankorder measure of performance were not designed to yield a measure of how many stimuli were retained, for example. Thus, their pigeons' above-chance discrimination could have been accomplished with considerably fewer than the 320 pictures being memorized. Furthermore, the testing of all 320 stimuli was quite brief, making it impossible to judge the long-term effects of high memory load. Since then, the capacity of pigeons to remember large numbers of pictures has been confirmed. Von Fersen and Delius (1989) used a two-alternative choice proce- 
dure that required pigeons to discriminate between 100 and 625 arbitrary geometric shapes. Various tests suggested that the pigeons had learned a large number of these images, but the asymmetrical nature of the discrimination makes determining any specific value difficult. Chase and Heinemann (2001) have reported an unpublished study in which pigeons were trained to 640 randomly assigned pictures in a two-alternative choice task to a level of approximately $80 \%$ correct.

Thus, beyond the fact that pigeons can likely hold about 300 pictures in memory for months at a time, little can be said about how the pigeons accomplish this or even if this is near their capacity. To address this, we investigated the mechanisms of pigeon long-term associative memory in more detail than previously have been attempted. Two pigeons were tested in a choice task that required them to report whether the right or the left response (randomly assigned) was correct for any particular picture. Because of this arbitrary choice assignment, the only solution was to memorize each picture and its associated correct response. This additional associative component makes their task much more demanding than the yes/no recognition tasks testing human pictorial capacity (e.g., Shepard, 1967).

To examine capacity, we increased memory load by constantly adding new sets of picture-response associations for the pigeons to memorize. Once each new set was mastered, its items were shifted to the constantly increasing pool of old-item pictures that were simultaneously being sampled and tested. This continuous sampling of old items allowed us to assess the status and content of the pigeons' long-term memories for the growing number of picture-response associations tested over the first 3 years of the project. This article reports that pigeons have a very large exemplar-based long-term memory system and, for the first time in any species, that there is an apparent limit to the amount of information that might be simultaneously maintained in such a memory system.

\section{METHOD}

\section{Animals}

Two male Silver King pigeons, maintained at $80 \%-85 \%$ of their free-feeding weight, were tested. They had memorized 40 stimuli while learning an equivalence discrimination 3 months earlier.

\section{Apparatus}

Testing was done in a black chamber $(38 \times 36 \times 38 \mathrm{~cm})$ controlled by a microcomputer. The stimuli were presented on a color monitor (NEC MultiSync C500; $800 \times 600$ pixels, 16-bit color resolution) visible through a window in the middle of the chamber's front panel. Pecks to the monitor were detected by an infrared lightemitting diode (LED) touchscreen (Carroll Touch, supplied by EloTouch Systems). A houselight was located in the ceiling and was illuminated at all times, except time-outs. Identical food hoppers (Coulbourn E14-10) were located in the chamber's right and left walls, $3 \mathrm{~cm}$ from the front panel. Infrared LEDs mounted $2.5 \mathrm{~cm}$ in front of each hopper detected the approach of the bird's head toward the hopper, indicating its right/left choice. The left hopper contained safflower, and the right contained mixed grain.

\section{Procedure}

Trials started with a peck to a centrally presented $2.5-\mathrm{cm}$ white signal. This was followed by the presentation of a $480 \times 300$ pixel picture. These pictures were drawn from different image collections and the Internet and consisted of a very wide variety of landscapes, objects, and abstract photography. After three to eight pecks (randomly determined) to the picture, the lights inside the right/left choice hoppers were illuminated. The pigeon then made its choice by entering one of the two hoppers. If the correct hopper was entered, it was raised for $2.4 \mathrm{sec}$. If the incorrect hopper was entered, the hopper lights were turned off, and the houselight was extin-

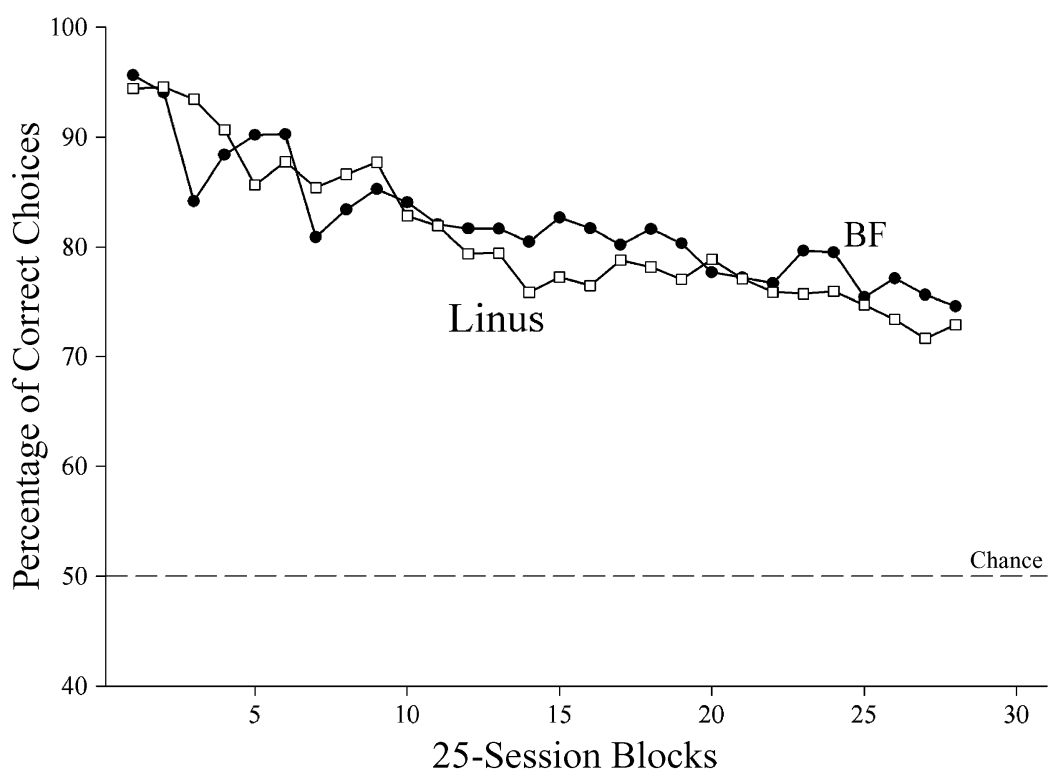

Figure 1. Mean percentage correct on old-items trials across the entire 700 sessions (in 25-session blocks) of testing for each pigeon. 
guished for $5 \mathrm{sec}$. A 3-sec intertrial interval followed either outcome. A correction procedure was used, with each trial repeated until a correct choice was executed. Correction trials were excluded from the analyses.

Daily sessions consisted of 120 trials (60 old- and 60 new-item trials) for the vast majority of the experiment (this varied slightly, depending on concurrently tested stimulus-analytic procedures not described here). The 60 new-item trials consisted of two repetitions of a set of 30 new stimuli. The correct responses to these new stimuli were randomly assigned (15 to each side). When a pigeon reached an accuracy of $85 \%$ for two consecutive sessions with this new set, it was shifted to the old-item pool, and a new 30 -item set was introduced. Pictures for the 60 old-item trials were selected at random from the increasing pool of learned stimuli.

Over the experiment, there were several minor procedural changes. Prior to the 19 th new set, only 20 stimuli were introduced with each new set, and 80 old-item trials were conducted each session (an occasional stimulus-analytic test sometimes used only 16 new stimuli). Prior to the 200th session, a different type of touchscreen (EMS Systems, Champaign, IL) was used, the left hopper delivered $3.5 \mathrm{sec}$ of safflower immediately, and the right hopper delivered $2.5 \mathrm{sec}$ of mixed grain after a delay of $1 \mathrm{sec}$. These modifications produced no adverse effects on performance. Any accidentally duplicated pictures were immediately removed from testing $(n<8)$.

During the first 3 years of this experiment, the 2 pigeons, BF and Linus, completed over 700 sessions of testing with this protocol. BF learned 61 sets of new items (eighteen 20-item sets, forty 30 item sets, and three test sets), and Linus learned 68 sets (eighteen 20 -item sets, forty-five 30 -item sets, and five test sets). This article presents the results from the first 700 test sessions.

\section{RESULTS}

Overall, the pigeons showed a remarkable capacity to learn and remember very large numbers of pictureresponse associations. Over the last 75 sessions of the 700 -session testing period, Linus performed at $73 \%$ accuracy with a memory set of 1,825 old-item pictures, and BF performed at $73 \%$ accuracy with a memory set of 1,648 pictures. Figure 1 shows the gradual decline in old-item accuracy over the course of testing (25-session blocks) as memory load increased. Starting with very high old-item accuracy when the memory set numbered a few hundred, performance gradually declined as items were added.

The rate at which the pigeons learned new item sets did not change during the experiment. In Figure 2, the mean rates of new-item acquisition for the first and the last 15 sets for each bird are compared. Neither pigeon showed any significant difference in how quickly these items were learned, as measured by sessions to criterion $[\mathrm{BF}$, first $15=7.2$ sessions, last $15=7.4$ sessions, $F(1,28)<1$; Linus, first $15=9.4$ sessions, last $15=7.4$ sessions, $F(1,28)=3.91$; an alpha level of $p<.05$ was used to judge all statistical significance]. The consistent rate at which new items were learned indicates that the decline in accuracy in Figure 1 was specifically associated with an increasing difficulty in recognizing old items, rather than with any nonspecific deterioration of performance.
To examine how the temporal separation between repetitions of the same item affected accuracy, we computed a lag function for the old items at two points in testing (first and last 200 sessions). Figure 3 shows old-item choice accuracy as a function of the number of trials between presentations of a particular item. Each point groups all the lags occurring within a span of 240 total trials (i.e., two sessions, minus correction trials). Early in training, the pigeons showed a strong recency effect, with the subsequent repetition of more recently presented items showing a benefit. Over the last 200 sessions of testing, when the old-item memory set was substantially larger and the frequency of item repetition considerably reduced, they showed a reduced benefit of recent item repetition, although a recency effect was still present. Included in Figure 3 are the best-fitting regression lines for each function. Each pigeon showed a statistically significant linear decline with increasing lag that captured $30 \%-40 \%$ of the variance for BF and $50 \%-60 \%$ for Linus. Nevertheless, items last seen over 60 sessions ago (approximately $2.5-3$ months of testing) still supported mid-70\% accuracy, suggesting that these picture-response memories were durable and stable.

We next looked at the old-item serial position functions. Figure 4 shows accuracy over the last 400 sessions (in 100-session blocks) as a function of when each set was learned (set serial position). The pigeons generally showed a U-shaped function. They did best with the items acquired earliest in training at all points during testing. In addition, the pigeons did well with recently learned items, as is indicated by the upward slope in accuracy toward the right side of each curve. This suggests that both frequency of presentation and recency of acquisition contributed to item retention.

In the next analyses, we examined how long it took the pigeons to recognize each picture. If the pigeons were searching their memory in parallel, one would expect little change in their choice reaction time (RT) as a function of memory load. If, however, they searched their memory serially, one should see a gradual lengthening of RT as items were added. One key to understanding their choice behavior in this task is to recognize that it was highly predictable from the location of their first peck to the stimulus. Over the last 200 sessions $(>23,000$ choices), $88 \%$ of BF's and $72 \%$ of Linus's initial responses were located to one or the other side of the display ( $>50$ pixels from the picture's midline). Of these spatially directed trials, they subsequently chose the hopper on the same side as the first peck $85.5 \%$ of the time (BF, 87.7\%; Linus, $83.5 \%$ ). For those trials in which the pigeons most strongly pecked left or right ( $>100$ pixels from the display's midline; $n=10,473$ ), this value climbed to $91 \%$. Thus, on a large majority of the trials, the pigeons operationally indicated their upcoming choices by their first peck's location. To produce such spatially directed pecking behavior, the pigeons would have needed to have already recognized the stimulus and 

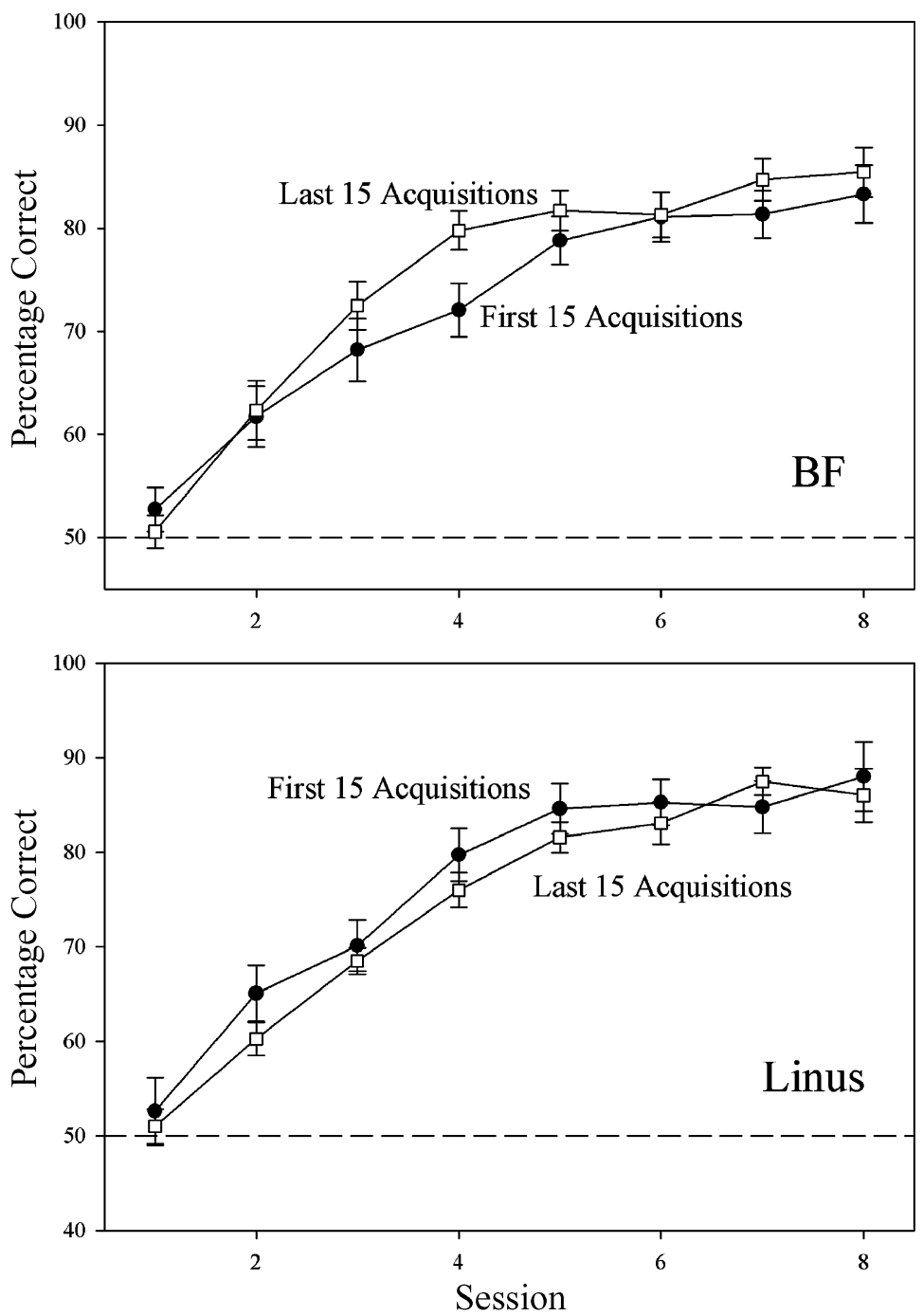

Figure 2. Mean percentage correct following the introduction of new-items trials for the first and the last 15 sets of items learned for each bird. Error bars show the standard errors of the means, and the dotted lines show chance performance.

recalled its associated response prior to its execution. As a result, this time to first peck provides an excellent index to how long it took the pigeons to recognize an old picture and retrieve its response assignment.

With this estimate of search and choice time, Figure 5 shows first-peck RTs for correct and incorrect old-item choices from the last 500 sessions of testing for those trials in which the pigeons showed a strong directional response ( $>100$ pixels from display midline). Two facts are particularly important. The first is that initial responses to pictures on correct trials $(1,389 \mathrm{msec})$ were significantly faster than those on incorrect trials $(1,648 \mathrm{msec})$. This was true for both pigeons [BF, correct $=1,522 \mathrm{msec}$, incorrect $=1,782 \mathrm{msec}, F(1,18)=6.0$; Linus, correct $=$ $1,257 \mathrm{msec}$, incorrect $=1,514 \mathrm{msec}, F(1,18)=7.5]$. Second, none of these latencies significantly changed over the 500 sessions of testing despite the increasingly greater memory load $[F(9,9) \leq 2.5]$, suggesting that olditem memories were being accessed in parallel. For the remaining trials with no or little directional bias, the pigeons were generally faster overall and showed a reduced difference between correct and incorrect trials (BF, correct $=1,397 \mathrm{msec}$, incorrect $=1,488 \mathrm{msec}$; Linus, correct $=908 \mathrm{msec}$, incorrect $=967 \mathrm{msec}$ ).

\section{DISCUSSION}

This experiment indicates that pigeons have a much larger capacity for stimulus-specific associative information than previously had been established. Both pigeons' performances declined with increasing memory load over testing but were still well above $70 \%$ accuracy 


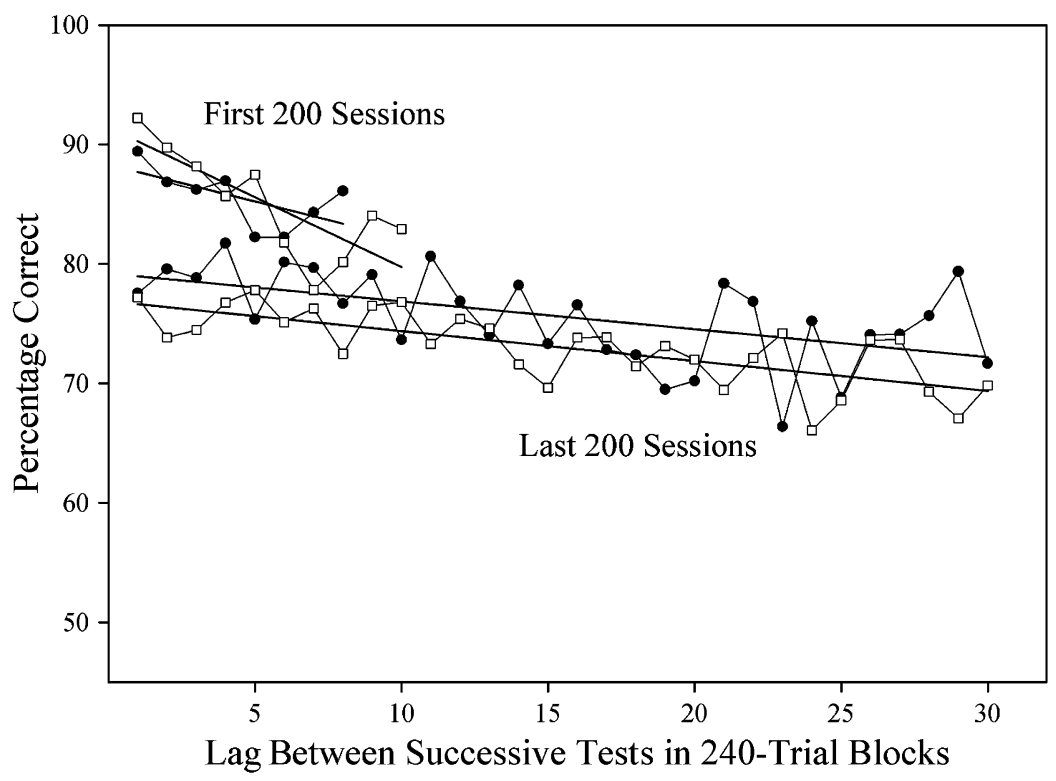

Figure 3. Mean percentage correct as a function of the number of trials (lag) between successive tests of an old item for the first and last 200 sessions of testing. Lags have been grouped into blocks of 240 trials. The open squares show the data from Linus, and the filled dots show the data from BF. The additional lines fitted to each curve show the best-fitting regression lines. Lags longer than those shown did occur, due to the random selection procedure, but were excluded because of the substantially smaller number of observations.

with between 1,600 and 1,800 items in their old-item memory set. The key question is just how much of this information was retained and involved in their discrimination. Because of our choice procedure, a reasonable estimate can be provided. Assuming that performance is a mixture of remembered and forgotten items, a simple all-or-none high-threshold model can be used to estimate capacity. This previously used model corrects for guessing and provides an index to the number of fully encoded items required to account for their discrimination (see Standing, 1973). It assumes that performance is an additive combination of trials controlled by memory (probability correct $=1$ ) and trials in which the pigeons guess (probability correct $=.5$ ), and the size of the discrimination set is estimated by deriving the best-fitting probability, mixing these two trial types.

Figure 6 shows the estimated number of memorized pictures needed to account for each bird's discrimination performance over the experiment in 25-session blocks (approximately 1-month intervals). Early on, the estimated discrimination set increased linearly with the addition of each new set. Over the last 225 sessions ( $\approx 9$ months) for Linus and over the last 150 sessions ( $\approx 6$ months) for $\mathrm{BF}$, however, these estimates seem to have reached an asymptote. To better quantify these conclusions, the values of the estimated discrimination set were subjected to a series of linear regressions over successive 9-block segments of each curve. Table 1 shows the slope coefficients from these analyses. Up until the beginning of the segments starting with the 14th (BF) and 18th (Linus) blocks, both pigeons showed stable and highly linear increases in estimated set size. Beginning at these points, the estimated slopes began to systematically decrease. Over the last 9 blocks, neither pigeon's data showed a significant linear slope $[F \mathrm{~s}(1,8)<3.5]$. Over the last 6 blocks, the average estimated memory size was 845 pictures for BF and 822 pictures for Linus. These data indicate that for this particular task, we seem to have reached a limit in how much stimulus-specific pictorial information could be retained by the pigeons. To our knowledge, this is the first such capacity limitation empirically demonstrated for any nonworking memory paradigm in any species.

Does this mean these pigeons were full? No. One can be reasonably sure that they could have learned another simple discrimination task (e.g., vertical vs. horizontal), with little loss to the current pictorial memory task. Furthermore, neither slope in the above estimates reached zero. What does seem clear, however, is that some kind of cognitive limitation was beginning to substantively impact the pigeons' previously excellent performance. Other memory metrics might produce terminal values different from those estimated (for instance, our model does not distinguish between 830 fully encoded items and a much larger set consisting of partial representations of each picture); the critical point is that the change in estimated slope strongly indicates a growing limitation in their capacity to discriminate more items. This likely represents a boundary between the competing demands of constantly acquiring new information and retaining long-term access to all of the previous picture-response 


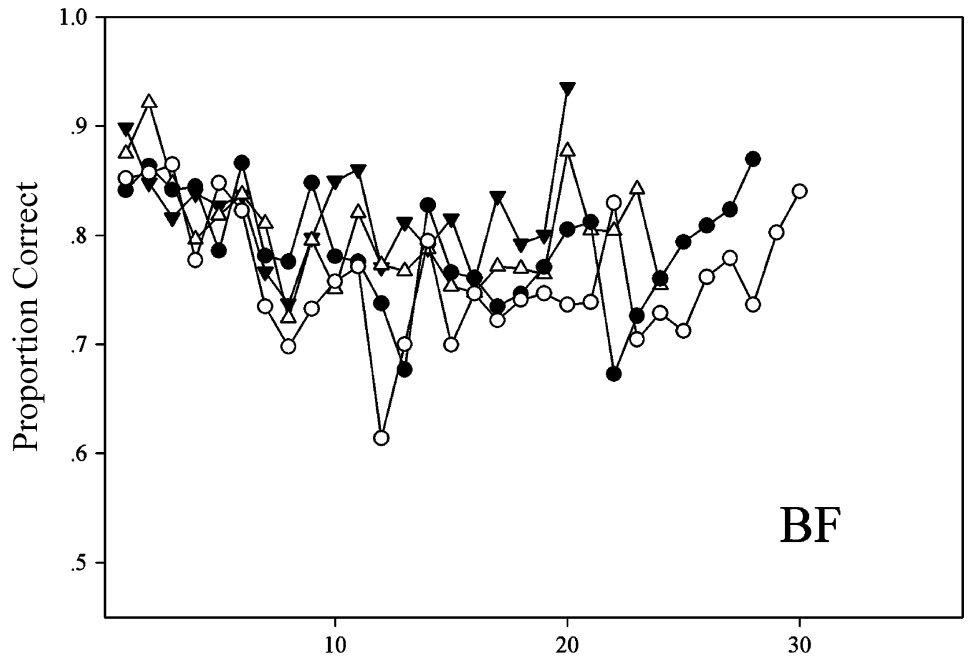

Set Serial Position (2-set blocks)

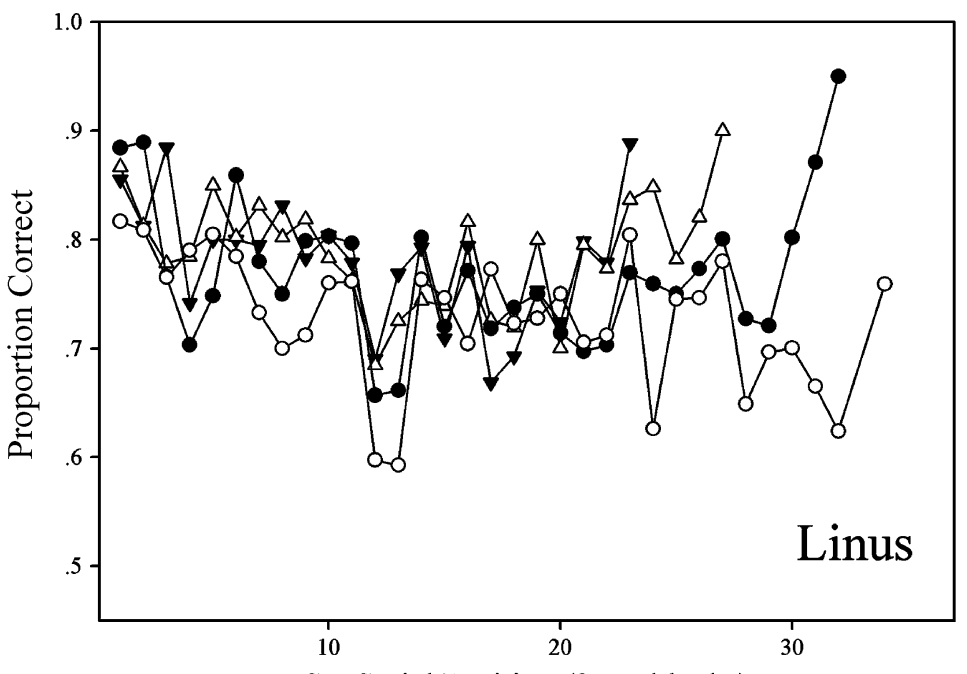

Set Serial Position (2-set blocks)

Figure 4. Mean proportion correct as a function of set serial position over the last 400 sessions. Each line represents a block of 100 sessions (dark triangles, 300-400; open triangles, 400-500; dark circles, 500-600; open circles, 600700). Individual sets have been grouped into blocks of adjacent sets.

associations. Several sources may contribute to this limit. One source may involve the encoding of the pictures. As the memory set increased, the number of bits of information required to distinguish among all of the items correspondingly increased. As such, the pigeons may have had increasing difficulty with separating each new item from previous old items and encoding it. This issue may even force old items to be recoded in new ways with time (e.g., memorizing just color might work for the first 100 items but would be an increasingly unreliable piece of information as the memory set grew). A second source may involve the number of "slots" actually available to retain items. In this sense, memory is actually filling up. A third source may lie with the facility of the long-term memory system in maintaining this information over time. Thus, as memory demands increase, greater interference between the items or the decay of stored information may cause a greater difficulty in recognizing each item. This process is likely reflected in the linearly declining performance with the growing lag between item tests. Whether the remarkable equivalence in this estimated limit across the 2 birds is cognitively meaningful or just a fortuitous convergence cannot be determined without additional subjects.

Besides this limit, other properties of long-term associative memory were also identified. First, access to this store of associative memories was parallel in nature, as indicated by the short and flat nature of their first-peck 


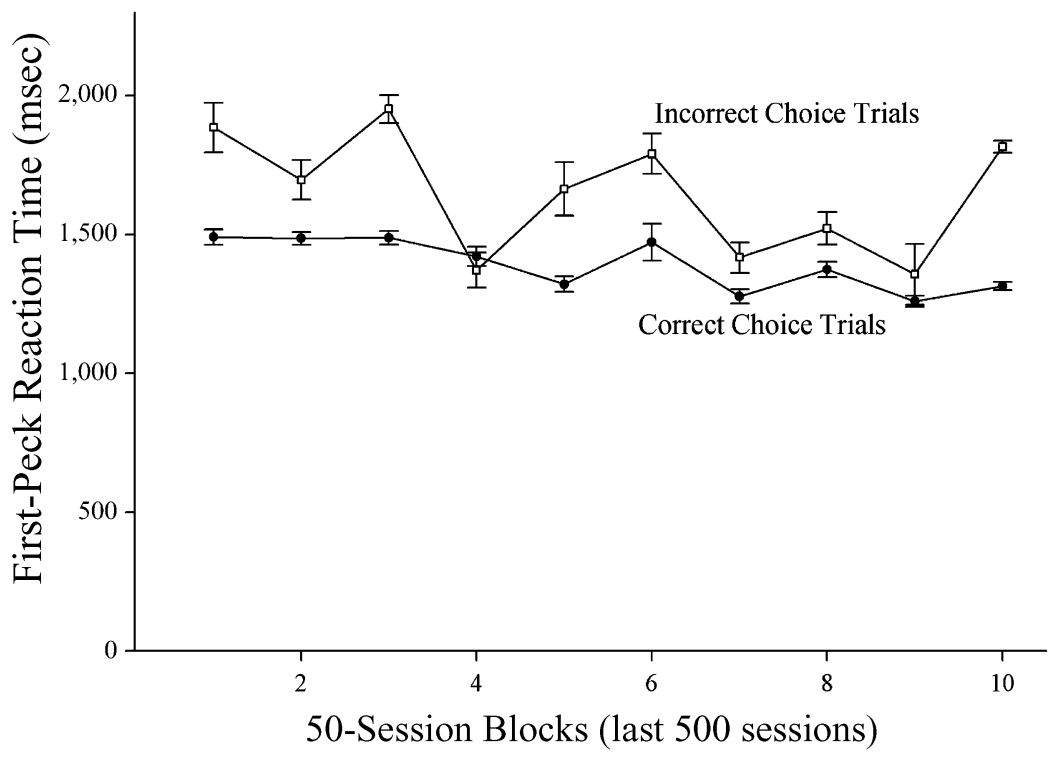

Figure 5. Mean first-peck reaction time for correct and incorrect old-item trials over the last 500 sessions of testing. Error bars show the average standard errors of the means across birds for each block.

RTs over increasing memory items. Since a peck takes approximately 500-600 msec to execute, our data suggest that it took approximately $500-1,000 \mathrm{msec}$ to search and retrieve the correct item from memory. The longer RTs for incorrect trials does suggest that an additional process is present on these trials. This may reflect further memory search, competing responses derived from uncertainty, or partial recovery of multiple items that interfere with each other in generating a response. Second, the classic U-shaped nature of the serial position function suggests that their memories were a combination of wellconsolidated early memories, likely due to their higher repetition rate early in training and overall greater exposure, and recently acquired memories, due to their relative recency. These indicate that their memory is not of a simple first-in/ first-out design. Finally, whatever the na-

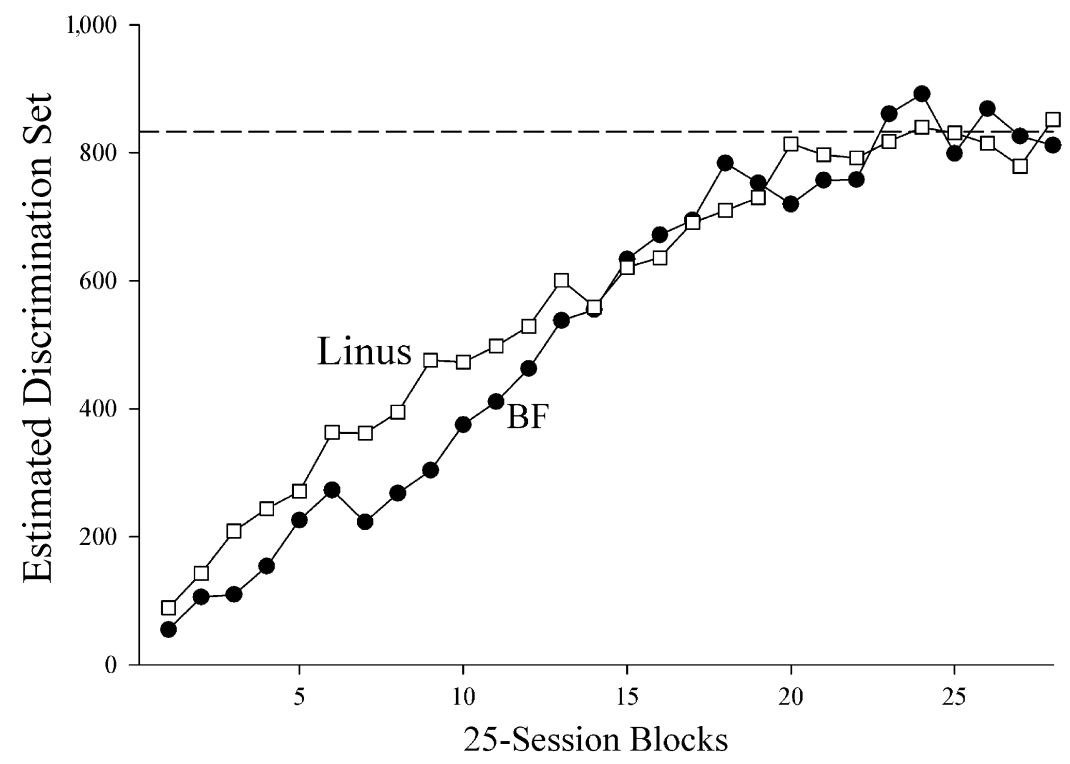

Figure 6. Estimated number of items in memory as derived by a simple correction for the guessing model (see the text). Dotted line represents the average estimated discrimination set as derived over the last six blocks of testing. 
Table 1

Slope Coefficients for Successive Nine-Block Segments of the Estimated Discrimination Set for Each Pigeon

\begin{tabular}{ccc}
\hline Segment & BF & Linus \\
\hline 1 & .952 & .989 \\
2 & .951 & .985 \\
3 & .955 & .981 \\
4 & .954 & .977 \\
5 & .948 & .976 \\
6 & .966 & .960 \\
7 & .997 & .962 \\
8 & .997 & .959 \\
9 & .994 & .962 \\
10 & .994 & .973 \\
11 & .982 & .971 \\
12 & .930 & .963 \\
13 & .893 & .960 \\
14 & .893 & .963 \\
15 & .843 & .963 \\
16 & .771 & .938 \\
17 & .717 & .910 \\
18 & .697 & .811 \\
19 & .717 & .436 \\
20 & .580 & .305 \\
\hline
\end{tabular}

ture of the forgetting process, its progress seems to be linear in nature, but slow acting enough that lags of several months or more can easily be tolerated.

The ease of the present task suggests that the ability to retain large amounts of visual information is an important and adaptive ability for these animals. Several other lines of investigation have also hinted that pigeons can be extremely stimulus specific. This can be seen in their reactions when memorizing exemplars (Chase \& Heinemann, 2001; Vaughan \& Greene, 1984), pictorial details (Edwards \& Honig, 1987; Greene, 1983), object orientations (Peissig, Young, Wasserman, \& Biederman, 2000; Spetch \& Friedman, 2003), and stimulus relations (Carter \& Werner, 1978; Wright, 1997). In fact, the capacity to memorize specific exemplars and events may represent a fundamental and general adaptation of the avian nervous system. Various species of birds have been found to have durable long-term memories for specific foraging (Henderson, Hurly, \& Healy, 2001) and migratory (MettkeHoffman \& Gwinner, 2003) experiences. Within the auditory modality, reports have indicated that some birds can distinguish among relatively large numbers $(<64)$ of conspecific songs (Chew, Vicario, \& Notebohm, 1996; Stoddard, Beecher, Loesche, \& Campbell, 1992), and mockingbirds have learned repertoires of 150 or more heterospecific songs (Derrickson, 1987). The Clark's nutcracker has been found to have a large capacity memory for self-generated, spatially related, caching experiences (Tomback, 1980). It has been indirectly estimated that a nutcracker creates approximately 3,000-6,000 cache sites during the fall and recovers seeds from these sites over the winter. It has been demonstrated in the laboratory that these birds can remember at above-chance levels $18-25$ caches, in a room containing 69 cache sites, for as long as 180-285 days (Balda \& Kamil, 1992).
Such findings suggest that birds may rely on the learning and retention of long-term memories for specific information to guide much of their behavior, and this may represent their primary or preferred strategy for acquiring information. As such, all birds may have an enhanced capacity to memorize specific experiences and associated specifics. Given the initial evolution of a simple network circuit for storing associative information about a specific stimulus and its consequences, it is easy to imagine that multiplying and replicating this circuit many times over to build a large-capacity, event-specific, database memory system would be a relatively easy cognitive enhancement to evolve. If birds are predisposed to memorize specific experiences, this would suggest that the specialized spatial memory capacity in food-storing birds might have evolved from this fundamental avian capacity and then been refined for the spatial demands of their niche.

If birds do rely extensively on specific memories to guide their behavior, this raises the question of how to deal with the increasing number of recent experiments that have suggested that pigeons can also learn both perceptual and relational concepts (Astley \& Wasserman, 1992; Cook, Katz, \& Cavoto, 1997; Cook, Kelly, \& Katz, 2003; Herrnstein \& Loveland, 1964). Given this, how should these two apparently distinct forms of stimulus control, one causing the individual stimuli to be subordinate and transparent to the overarching concept and the other requiring each item to have its own separate representation, be reconciled? As has been argued in the human categorization literature, two resolutions are plausible. One suggestion is that these two types of stimulus control are relatively independent of one another and are mediated by different mechanisms (Ashby, AlfonsoReese, Turken, \& Waldron, 1998; Erickson \& Kruschke, 1998), involving separate rule-based and exemplar-based mechanisms. The other possibility is to suggest that these two types of control reflect the operation of only a single mechanism. For instance, exemplar-based theories of human classification, object recognition, automaticity, and decision making (Brooks, 1978; Hintzman, 1988; Nosofsky, 1986; Tarr \& Bülthoff, 1998) have been successful in accounting for many aspects of human cognition. The simplicity of these theories makes them equally attractive for application to animals (Astley \& Wasserman, 1992; Chase \& Heinemann, 2001), especially given any substantial storage capacity (i.e., the present results). It will be important to determine whether single-process exemplar approaches can account for the conceptual-like data collected with animals or whether additional, rulebased mechanisms will indeed also be needed.

\section{REFERENCES}

Ashby, F. G., Alfonso-Reese, L. A., Turken, U., \& Waldron, E. M. (1998). A neuropsychological theory of multiple systems in category learning. Psychological Review, 105, 442-481.

Astley, S. L., \& Wasserman, E. A. (1992). Categorical discrimination and generalization in pigeons: All negative stimuli are not created 
equal. Journal of Experimental Psychology: Animal Behavior Processes, 18, 193-207.

BALDA, R. P., \& KAMIL, A. C. (1992). Long-term spatial memory in Clark's nutcracker, Nucifraga columbiana. Animal Behaviour, 44, 761-769.

BrooKs, L. R. (1978). Non-analytic concept formation and memory for instances. In E. Rosch \& B. Lloyd (Eds.), Cognition and categorization (pp. 169-211). Hillsdale, NJ: Erlbaum.

Carter, D. E., \& Werner, J. T. (1978). Complex learning and information processing in pigeons: A critical analysis. Journal of the Experimental Analysis of Behavior, 29, 565-601.

Chase, S., \& Heinemann, E. G. (2001). Exemplar memory and discrimination. In R. G. Cook (Ed.), Avian visual cognition [On line]. Available at www.pigeon.psy.tufts.edu/avc/chase/.

Chew, S. J., Vicario, D. S., \& Notebohm, F. (1996). A large-capacity memory system that recognizes the calls and songs of individual birds. Proceedings of the National Academy of Sciences, 93, 1950-1955.

CoOK, R. G., KatZ, J. S., \& CAVOTO, B. R. (1997). Pigeon same-different concept learning with multiple stimulus classes. Journal of Experimental Psychology: Animal Behavior Processes, 23, 417-433.

CoOK, R. G., Kelly, D. M., \& KatZ, J. S. (2003). Successive two-item same-different discrimination and concept learning by pigeons. $\mathrm{Be}$ havioural Processes, 62, 125-144.

DERRICKSON, K. C. (1987). Yearly and situational changes in the estimate of repertoire size in northern mockingbirds (Mimus polyglottos). Auk, 104, 198-207.

DudaI, Y. (1997). How big is human memory, or on being just useful enough. Learning \& Memory, 3, 341-365.

EDWARDS, C. A., \& Honig, W. K. (1987). Memorization and "feature selection" in the acquisition of natural concepts in pigeons. Learning \& Motivation, 18, 235-260.

Erickson, M. A., \& KruschKe, J. K. (1998). Rules and exemplars in category learning. Journal of Experimental Psychology: General, 127, 107-140.

GREENE, S. L. (1983). Feature memorization in pigeon concept formation. In M. L. Commons, R. J. Herrnstein, \& A. R. Wagner (Eds.), Quantitative analyses of behavior: Discrimination processes (Vol. 4, pp. 209-229). Cambridge, MA: Ballinger.

Henderson, J., Hurly, T. A., \& HeAly, S. D. (2001). Rufous hummingbirds' memory for flower location. Animal Behaviour, 61, 981-986.

Herrnstein, R. J., \& Loveland, D. H. (1964). Complex visual concept in the pigeon. Science, 146, 549-551.

Hintzman, D. L. (1988). Judgments of frequency and recognition memory in a multiple-trace memory model. Psychological Review, 95, 528-551.
LANDAuer, T. K. (1986). How much do people remember? Some estimates of the quantity of learned information in long-term memory. Cognitive Science, 10, 477-493.

MEtTKe-Hoffman, C., \& GWINNER, E. (2003). Long-term memory for a life on the move. Proceedings of the National Academy of Sciences, 100, 5863-5866.

MiLler, G. A. (1956). The magical number seven, plus or minus two: Some limits on our capacity for processing information. Psychological Review, 63, 81-97.

NELSON, C. (2001). The magical number 4 in short-term memory: A reconsideration of mental storage capacity. Behavioral \& Brain Sciences, 24, 87-185.

Nosofsky, R. M. (1986). Attention, similarity, and the identificationcategorization relationship. Journal of Experimental Psychology: General, 115, 39-57.

Peissig, J. J., Young, M. E., Wasserman, E. A., \& Biederman, I. (2000). Seeing things from a different angle: The pigeon's recognition of single geons rotated in depth. Journal of Experimental Psychology: Animal Behavior Processes, 26, 115-132.

SHEPARD, R. N. (1967). Recognition memory for words, sentences, and pictures. Journal of Verbal Learning \& Verbal Behavior, 6, 156-163.

Spetch, M. L., \& FrIEDMAN, A. (2003). Recognizing rotated views of objects: Interpolation versus generalization by humans and pigeons. Psychonomic Bulletin \& Review, 10, 135-140.

STANDING, L. (1973). Learning 10,000 pictures. Quarterly Journal of Experimental Psychology, 25, 207-222.

Stoddard, P. K., Beecher, M. D., Loesche, P., \& Campbell, S. E. (1992). Memory does not constrain individual recognition in a bird with song repertoires. Behaviour, 122, 274-287.

TARR, M. J., \& BülthoFf, H. H. (1998). Image-based object recognition in man, monkey and machine. Cognition, 67, 1-20.

Toмваск, D. F. (1980). How nutcrackers find their seed stores. Condor, 82, 10-19.

Vaughan, W., \& Greene, S. L. (1984). Pigeon visual memory capacity. Journal of Experimental Psychology: Animal Behavior Processes, 10, 256-271.

Von Fersen, L., \& Delius, J. D. (1989). Long-term retention of many visual patterns by pigeons. Ethology, 82, 141-155.

Wright, A. A. (1997). Concept learning and learning strategies. Psychological Science, 8, 119-123.

(Manuscript received November 14, 2003; revision accepted for publication May 10, 2004.) 